\title{
Factors affecting the quality of life in women with gestational diabetes mellitus: a path analysis model
}

\author{
Soheila Ansarzadeh ${ }^{1}$, Leili Salehi ${ }^{2,3^{*}}$, Zohreh Mahmoodi ${ }^{4}$ and Abolfazl Mohammadbeigi ${ }^{5}$
}

\begin{abstract}
Background: Quality of life (QoL) is the most important indicator for assessing the status of health care in chronic diseases. The present study aimed to determine the pathway determinants model of QoL in patients with gestational diabetes mellitus (GDM).

Methods: This cross-sectional study was conducted on 329 women with GM referred to health care centers in Qom, Iran during 2018. Convenience sampling methods was used. Inclusion criteria were: afflicted by GM and received pregnancy care services from health center. Several questionnaires (Knowledge, attitude, self-efficacy (SE), social support (SS), pregnancy distress, self-management(SM) and QoL) were used for data collection. Data were analyzed with SPSS-21 and Lisrel-8.8 software using statistical path analysis.

Results: The mean age of participants was $30.93 \pm 5.42$ years. The final path model fitted well (CFI =1, RMSEA $=$ 0.0003) and showed that, only age variable from both direct and indirect path had an impact on QoL $(B=0.51)$. Among variables that directly affected the QoL, SS had the highest effect $(B=1.02)$ and SE $(B=0.01)$ had the lowest effect. In the indirect path, only the knowledge variable by affecting the SE had an impact on the QoL ( $B=0.0045)$.

Conclusion: SS had the greatest impact on the QoL. Obviously, providing all the requirements to support patients can help them overcome problems and improve their QoL. Distress negatively affects the QoL through SM and it should be noticed in interventional studies.
\end{abstract}

Keywords: Gestational diabetes, Quality of life, Path analysis, Iran

\section{Background}

Gestational diabetes (GD) as one of the main metabolic disorders in pregnancy has had an increasing trend in recent years [1]. It refers to glucose intolerance, which is diagnosed for the first time during pregnancy [2]. The disease affects approximately $6 \%$ of pregnancies in Iran, with an estimated prevalence of $1.3 \%$ to $18.6 \%$ [3]. Other outbreaks have been reported from different countries, varying from 6 to 13\% [4].

It is associated with various complications in the mother, fetus and neonatal, among which macrosomia

\footnotetext{
* Correspondence: leilisalehi@abzums.ac.ir; leilisalehi83@yahoo.com ${ }^{2}$ Department of Health Education and Promotion \& Research center for Health, Safety and Environment, Alborz University of Medical Sciences, Karaj, Iran

${ }^{3}$ Department of Health Education \& Promotion, School of Public Health, Alborz University of Medical Sciences, P.O. Box 3146-883811, Karaj, Iran Full list of author information is available at the end of the article
}

(which is defined as a birth weight over than $4 \mathrm{~kg}$ and/or above 90th percentile weight for gestational age or large for gestational age), asphyxia, stillbirth, hypoglycemia, and polycythemia may be present in neonates [5-7]. Preeclampsia, increased incidence of induction and cesarean section (CS), increased chances of developing type 2 diabetes, cardiovascular disease, and increased risk of diabetes in later pregnancies, delayed milk secretion from mammary glands are the common complications in mothers [8-11]. In addition, poor blood glucose control can increase maternal and neonatal mortality rates [12].

Quality of life (QoL) is the most important indicator for assessing the status of health care in chronic diseases [13]. The World Health Organization (WHO) defines QoL as the individuals' perception of their living conditions in the context of the value system of the surrounding environment

(c) The Author(s). 2020 Open Access This article is distributed under the terms of the Creative Commons Attribution 4.0 International License (http://creativecommons.org/licenses/by/4.0/), which permits unrestricted use, distribution, and reproduction in any medium, provided you give appropriate credit to the original author(s) and the source, provide a link to the Creative Commons license, and indicate if changes were made. The Creative Commons Public Domain Dedication waiver (http://creativecommons.org/publicdomain/zero/1.0/) applies to the data made available in this article, unless otherwise stated. 
[14]. DM affects the QoL in patients [15] and modifies the physical, psychological, and social abilities of patients [16]. QoL in women with gestational diabetes can indicates the different personal response to an appropriate medical treatment.

Identification of factors affecting the QoL in diabetic patients improves the patients' health and enhances their survival. In this regard, factors, such as diabetic knowledge, attitudes and self-management (SM) are considered as key factors that directly and indirectly affect a QoL in the patients [17]. Factors such as self -efficacy (SE) and social support (SS) are also influenced by SM behaviors, which can affect the QoL of patients [18]. Although, the role of intervening psychosocial factors, such as depression and stress, self-care (SC) behaviors and proper blood glucose control should be considered [19-21].

Few studies have examined the QoL relationships with other variables. For example, the relationship between SM behaviors and QoL [22] SC behaviors and stress [23] Knowledge, attitude and SE [22] SC and knowledge [24] SC behaviors and SS, demographic characteristics and QoL [25] SE, SS and QoL [26]. Therefore, it is necessary to develop a model that can evaluate the direct and indirect effects of these variables on the QoL as well as the relationship between influential variables.

Therefore, the present study aimed to determine the pathway determinants of QoL in patients with GDM. The proposed model showed association between knowledge, attitude, SE, SS, pregnancy distress, SM and age and body mass index (BMI) with QoL in women with GDM. The proposed model is shown in Fig. 1.

\section{Methods \\ Procedure}

This cross-sectional study was conducted on 329 women with GD referred to health care centers in Qom during 2018. First, all health clinics in Qom were identified. Then, we referred to the clinic, and obtained a list of patients, and then the patients with GD were identified. Then, by convenience sampling method, the subjects were selected to complete the sample size. In order to determine the sample size, the following formula was considered with the prevalence of $18 \%$ GD based on previous study in Iran [27], 95\% confidence interval and precision (d) of $4 \%$.

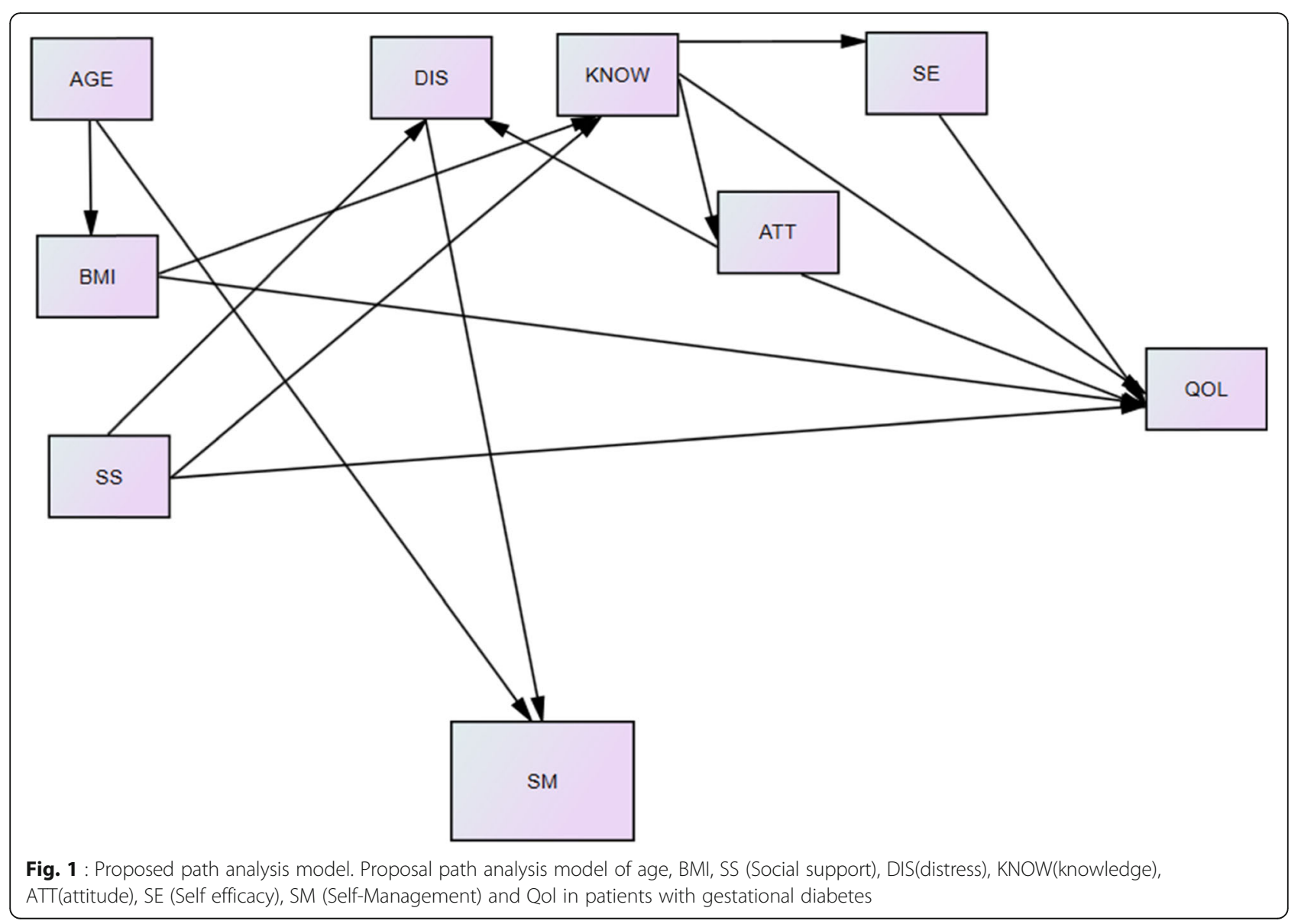




$$
\mathrm{n}=\frac{\mathrm{Z}_{(1-\alpha / 2)}^{2} \mathrm{P}(1-\mathrm{P})}{\mathrm{d}^{2}}
$$

The incomplete questionnaires were excluded from the study (7\% of the questionnaires) and finally 329 questionnaires were analyzed.

The study inclusion criteria were as follows: women who were diagnosed with GD according to the country's guide, and received pregnancy care services from one of the health care centers in Qom city.

To reach the people, telephone coordination was used and before the research tool was provided, the goals of the study and the willingness of people to participate in the study were evaluated, the written informed consent from the study participants was obtained, and the questionnaire was provided with the necessary explanations. The participants were asked to answer all the questions with accuracy. If participants had any doubts concerning how to fill each part, they were asked to contact the researcher. Some mothers tended to take the questionnaire home and fill it, which allowed them to fill in each questionnaire for about $60 \mathrm{~min}$. The ethics committee of Alborz University of Medical Sciences approved the study (Ethical Code: Abzums.ac.ir.1306.91.)

\section{Instruments}

Several questionnaires were used to collect data.

1. Demographic characteristics: include age, marital status, educational level, occupation, ethnicity, prepregnancy BMI, midwifery problems, pregnancy history, polycystic ovary syndrome, first-degree relatives, gastrointestinal tract control, and blood glucose control status.

2. Knowledge: A questionnaire containing 13 items was used that included 6 items regarding gestational diabetes and its risk factors, 4 items about screening and treatment, and 3 questions about the outcome of the disease in pregnancy that were answered by yes or no. This questionnaire was taken from the Elmurugan \& Arounassalame study [28], based on the classification of main designers of the questionnaire; 0-4 scores, indicating low knowledge, 5-8 representing medium, and above 9 representing appropriate knowledge. Validity and internal consistency of this questionnaire was evaluated by content validity and Kuder - Richardson respectively. The Kuder Richardson value was 0.75 .

3. Attitudes: The attitude questionnaire consisted of 12 items designed according to Anderson et al. [29] questionnaire. The attitude of women with gestational diabetes was assessed about receiving education for diabetes care, seriousness of the disease and glucose control importance. Higher scores represent a more positive attitude. The questionnaire is based on a fivepoint Likert scale ranging from 1 "completely disagree" to 5 "completely agree". The content validity was used
Table 1 Demographic Characteristics of Sample study $(n=$ 329)

\begin{tabular}{|c|c|}
\hline Variable & $\mathrm{N}(\%)$ \\
\hline \multicolumn{2}{|l|}{ Age } \\
\hline$<20$ & $6(1.8)$ \\
\hline $20-25$ & $43(13.1)$ \\
\hline $26-30$ & 103(31.3) \\
\hline $31-35$ & $110(33.4)$ \\
\hline $36-40$ & $58(17.6)$ \\
\hline$>40$ & $9(2.7)$ \\
\hline \multicolumn{2}{|l|}{ Marital Status } \\
\hline Married & $322(97.9)$ \\
\hline Single & $7(2.1)$ \\
\hline \multicolumn{2}{|l|}{ Occupation } \\
\hline Governmental & $24(7.3)$ \\
\hline /non-Governmental & $8(2.4)$ \\
\hline Housework & 297(90.3) \\
\hline \multicolumn{2}{|l|}{ Education } \\
\hline Illiterate & 65(19.75) \\
\hline High School & 207(62.92) \\
\hline University & $57(17.33)$ \\
\hline \multicolumn{2}{|l|}{ Ethnicity } \\
\hline Iranian & 298(90.58) \\
\hline Other & $31(9.42)$ \\
\hline \multicolumn{2}{|l|}{ BMI } \\
\hline$>18.5$ & $6(1.82)$ \\
\hline $18.24-24.9$ & $86(26.14)$ \\
\hline $25.9-29$ & 124(37.69) \\
\hline$>30$ & 113(34.35) \\
\hline \multicolumn{2}{|l|}{ Obstetric Complication } \\
\hline Yes & $111(33.74)$ \\
\hline No & $218(66.26)$ \\
\hline \multicolumn{2}{|l|}{ Wanted Pregnancy } \\
\hline Yes & $225(68.39)$ \\
\hline No & 104(31.61) \\
\hline \multicolumn{2}{|l|}{ PCO } \\
\hline Yes & $29(8.8)$ \\
\hline No & $300(91.2)$ \\
\hline \multicolumn{2}{|l|}{ Family History } \\
\hline Yes & $223(67.8)$ \\
\hline No & $106(32.2)$ \\
\hline \multicolumn{2}{|l|}{ Glucose Monitoring } \\
\hline Never & $18(5.47)$ \\
\hline Sometimes & $39(11.85)$ \\
\hline Once a week & $39(11.85)$ \\
\hline Daily & $82(24.92)$ \\
\hline Physician Recommendation & 151(45.90) \\
\hline \multicolumn{2}{|l|}{ Glucose Control } \\
\hline Nutrition & $162(49.24)$ \\
\hline Medication & 23(6.99) \\
\hline Insulin & 23(6.99) \\
\hline Mix & $121(36.78)$ \\
\hline
\end{tabular}


for the questionnaire validity and Cronbach's alpha coefficient for internal consistency (it was equal 0.82).

4. SE: To assess SE, the Paradly et al. [30] questionnaire was used. According this tool, the participants were asked to list their confidence to achieve certain behaviors related to diabetes control. This questionnaire consisted 35 items was scored based on a five- point likert scale (1. very sure, I cannot do it; 2 . Somewhat sure, I cannot do it; 3.not sure, if I can do it; 4. Somewhat sure, I can do it and 5. Very sure, I can do it). In order to calculate the score of SE, the items score was accumulated. Higher scores represent a more SE. The content validity was used for the questionnaire validity and Cronbach's alpha coefficient for internal consistency (it was equal 0.77).

5. SS: The SS questionnaire was used in diabetic individuals for SM. This questionnaire was designed by Naderi Magham et al. [31] and contained 30 questions that were scored based on a five- point likert scale from always (5) to never (1). This instrument includes nutritional subscales (9 questions), physical activity (5 questions), blood glucose monitoring (7 questions), foot care (6 questions) and smoking (3 questions). To calculate the scores at first we scored all items from 1 to 5 , second to calculate the row score for each subscale, we added item raw scores and then divide it to number of items in that subscale, third, to transfer row scores to a score ranging from 0 to 100 , we used the following formula to calculate the final score: The subscale score $=[$ (subscale row score -1$) / 4] \times 100$ [31]. This questionnaire was validated in Iran [31]

6. Pregnancy Distress: In this study, pregnancy distress was measured by Tilburg pregnancy distress questionnaire developed by Pop et al. [32] in 2011 and consisted of 16 items and two subscales. The first one is "Negative Affect" and the second is "Social (partner engagement). the first subscale includes 12 items and second subscale includes 4 items. The instrument items were scored based on a 4 -point Likert scale (0. Often, 1: quite often,
2: sometimes, and 3: rarely or never) the scores of 3rd, 5 th 6th, 7th, 9th 10th, 11th, 12th, 13th, 14th and 16th items were inversed. The minimum and maximum score is 0 and 48 respectively. The content validity was used for the questionnaire validity and Cranach's alpha coefficient for internal consistency (it was equal 0.75).

7. SM: SM questionnaire was developed by Schmitt et al. (2013) [33] in 2013. The questionnaire contains 16 questions, which are based on a 4-point Likert scale from 0 (does not apply to me) to 3 (very much apply to me). It includes different areas of SM includes glucose control, physical activity, nutrition, taking the services, and a question that evaluates SM in general. In order to calculate the score of each field, first, its scores were accumulated, then the sum of scores divided by 15 (all of which except the last one), multiplied by 10 , thus the score of each field was calculated. This questionnaire was valid based on expert panel views and reliable based on Cronbach's alpha coefficient. The Cronbach alpha coefficient was $0.83,0.79,0.81$, and 0.75 for glucose control, physical activity, nutrition and services respectively.

8. QoL: The World Health Organization Quality of Life questionnaire (WHOQOL-BREF) [34] was used. The questionnaire contained four subscales (such as physical health, mental health, social relationships, and environmental health) and a general score. This instrument was validated by Nejat et al. in Iran [35]..

For content validity a group of experts (10 specialists) evaluated the questionnaires and for determining the reliability, the Cranach's alpha coefficient was calculated.

\section{Data analysis}

All data were analyzed by using SPSS software version 21 and LISRELS software version 8 . First, the normality of the variables was evaluated using the KolmogorovSmirnov test.

The significance correlation between variables was considered as the first hypothesis of path analysis. Eight factors were identified as factors affecting QoL These

Table 2 Correlation of study variables $(n=329)$

\begin{tabular}{|c|c|c|c|c|c|c|c|c|c|}
\hline & Age & $\mathrm{BMI}$ & KNOW & ATT & SE & SS & DISS & SM & QoL \\
\hline Age & 1 & & & & & & & & \\
\hline BMI & $0.749^{* *}$ & 1 & & & & & & & \\
\hline KNOW & -0.169 & $-0.218^{*}$ & 1 & & & & & & \\
\hline ATT & -0.128 & -0.124 & $-0.157^{*}$ & 1 & & & & & \\
\hline SE & -0.111 & $-0.184^{* *}$ & $0.859^{* *}$ & $0.146^{*}$ & 1 & & & & \\
\hline SS & $-0.267^{* *}$ & $-0.233^{* *}$ & 0.096 & 0.061 & & 1 & & & \\
\hline DISS & $0.135^{*}$ & $0.147^{* *}$ & $-0.934^{* *}$ & $-0.166^{*}$ & $-0.853^{* *}$ & -0.101 & 1 & & \\
\hline SM & $-0.157^{*}$ & $-0.168^{*}$ & $0.848^{* *}$ & $0.133^{*}$ & $0.790^{* *}$ & $0.173^{* *}$ & $-0.857^{* *}$ & 1 & \\
\hline QoL & $-0.624^{* *}$ & $-0.788^{* *}$ & $0.198^{* *}$ & 0.086 & $0.164^{*}$ & $0.203^{*}$ & $-0.159^{*}$ & $0.138^{*}$ & 1 \\
\hline
\end{tabular}

BMI Body Mass Index, KNOW Knowledge, ATT Attitude, SE Self Efficacy, SS Social Support, DISS Distress, SM Self-Management, QoL Quality of Life

* was significant at level $0.05 ;{ }^{* *}$ was significant at level 0,01 
factors (knowledge, attitude, SE, SS, Pregnancy distress, $\mathrm{SM}$, age and BMI) were considered as independent variables and QoL was considered as a dependent variable.

In order to evaluate the fitness of the model, the fitting index such as $\times 2 / \mathrm{df}$, RMSEA (Root mean square error of approximation), CFI (Comparative fit index), GFI (Goodness of fit index), NFI (Normal fit index) and IFI (Incremental fit indices) were computed.

\section{Results}

\section{Characteristics of participants}

The mean age of participants was $30.93 \pm 5.42$ years. The majority of participants (73.0\%) had a history of disease in their first degree relatives. Most subjects (68.39\%) had wanted pregnancy.

$49.24 \%$ of subjects were controlled their diabetes by diet, $6.99 \%$ by drug and $\% 6.99$ by insulin injections. The rest of the subjects used a combination regime (e.g., nutrition and drug, nutrition and insulin, drug and insulin) (Table 1).

\section{Relationship between variables}

The correlation between variables is shown in Table 2 . A significant correlation was found between the variables and QoL varied from 0.14 to 0.79 . The strongest and reverse correlation was found between QoL and BMI (Table 2).

\section{Path analysis model}

The default relationship between the study variables was based on the evidence presented (Fig. 1). Based on existing literature and the correlation between variables, and according to the model indexes, the default model is tested in Fig. 2. Figure 2 shows the significant relationships of the variables based on the results of $t$ value. In

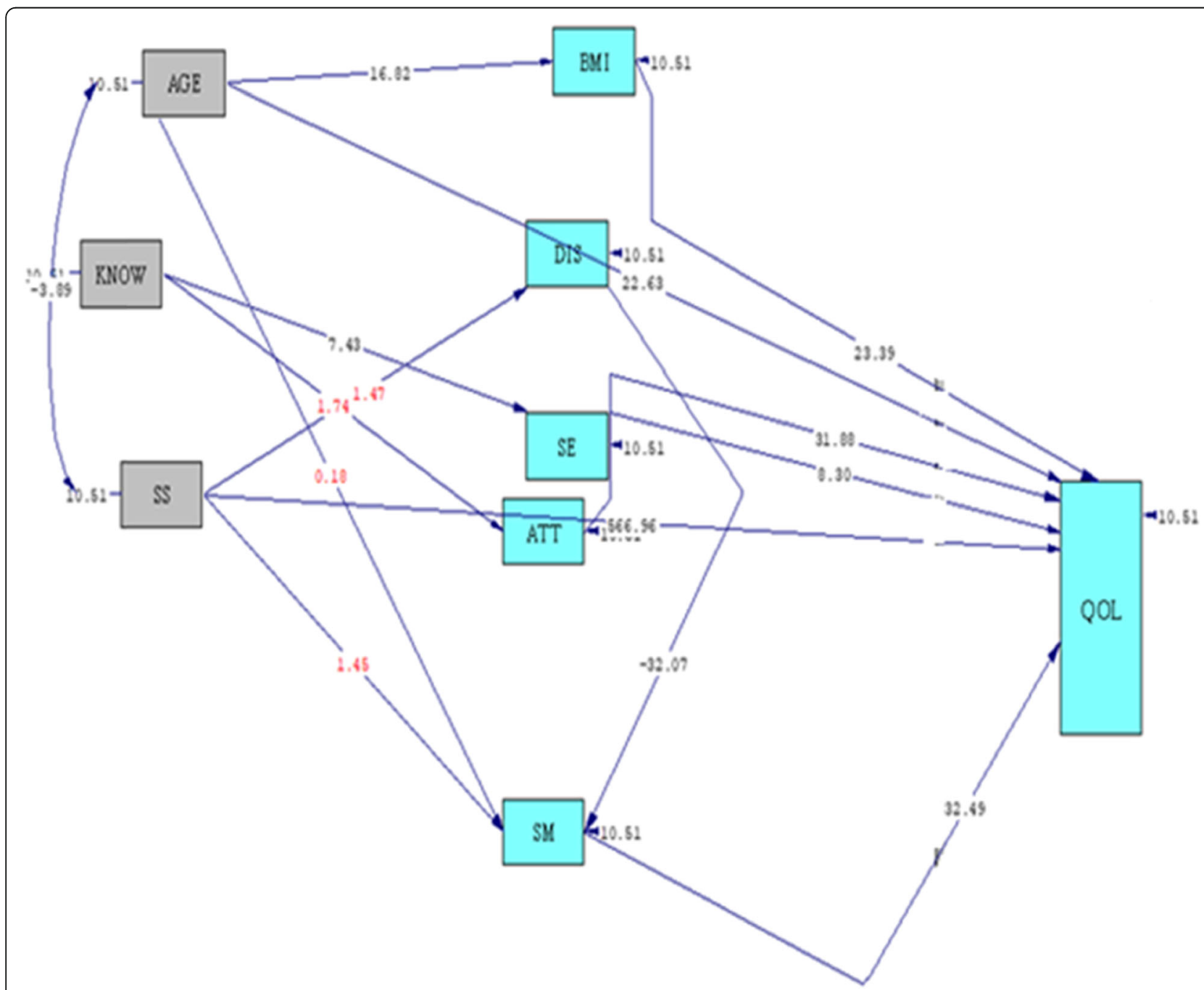

Fig. 2 Initial Path Analysis model (based on t-value). Initial path analysis model of age, BMI, knowledge, social support, distress, self efficacy, attitudes, self-management, and QoL in women with gestational diabetes. 
pathways that $\mathrm{t}$-value test is less than 1.96 is not significant and is indicated in red on the figure. But in other pathways that the value of $\mathrm{t}$-test is higher than 1.96, the pathway is significant. Accordingly, the pathways analysis, the indirect ways of SS through SM on QoL SS through distress on QoL, and the indirect path of age through SM on QoL were omitted due to insignificance relationships ( $\mathrm{t}$-value less 1.96).

In Fig. 3, the B standard is specified and non-significant pathways are removed. Based on the final model (Fig. 3), only age variable from both direct and indirect paths through $\mathrm{BMI}$ had an impact on $\mathrm{Qol}(\mathrm{B}=0.51)$. Among variables that directly affected the QoL, supports had the highest effect $(B=1.02)$ and $S E(B=0.01)$ had the lowest effect. In the indirect path, only the knowledge variable by affecting the SE had an impact on the QoL ( $\mathrm{B}=0.0045)$ (Table 3).
The final path model fitted well (CFI $=1$, RMSEA = 0.0003, GFI $=0.99$ ), the Goodness of fit Indices for the model indicated in Table 4. The mean and SD of the study variables presented in Table 5 . In the present study all variables that entered in the model, were quantitative.

\section{Discussion}

Based on the final fitted model, age had indirect and direct effects on QoL through BMI in women with GD. The significant negative effects of age on QoL in patients with diabetes are also shown in other studies [36-38]. Evidence shows an increase in undesirable side effects and improper pregnancy outcomes with increasing age which can affect QoL [39-41].

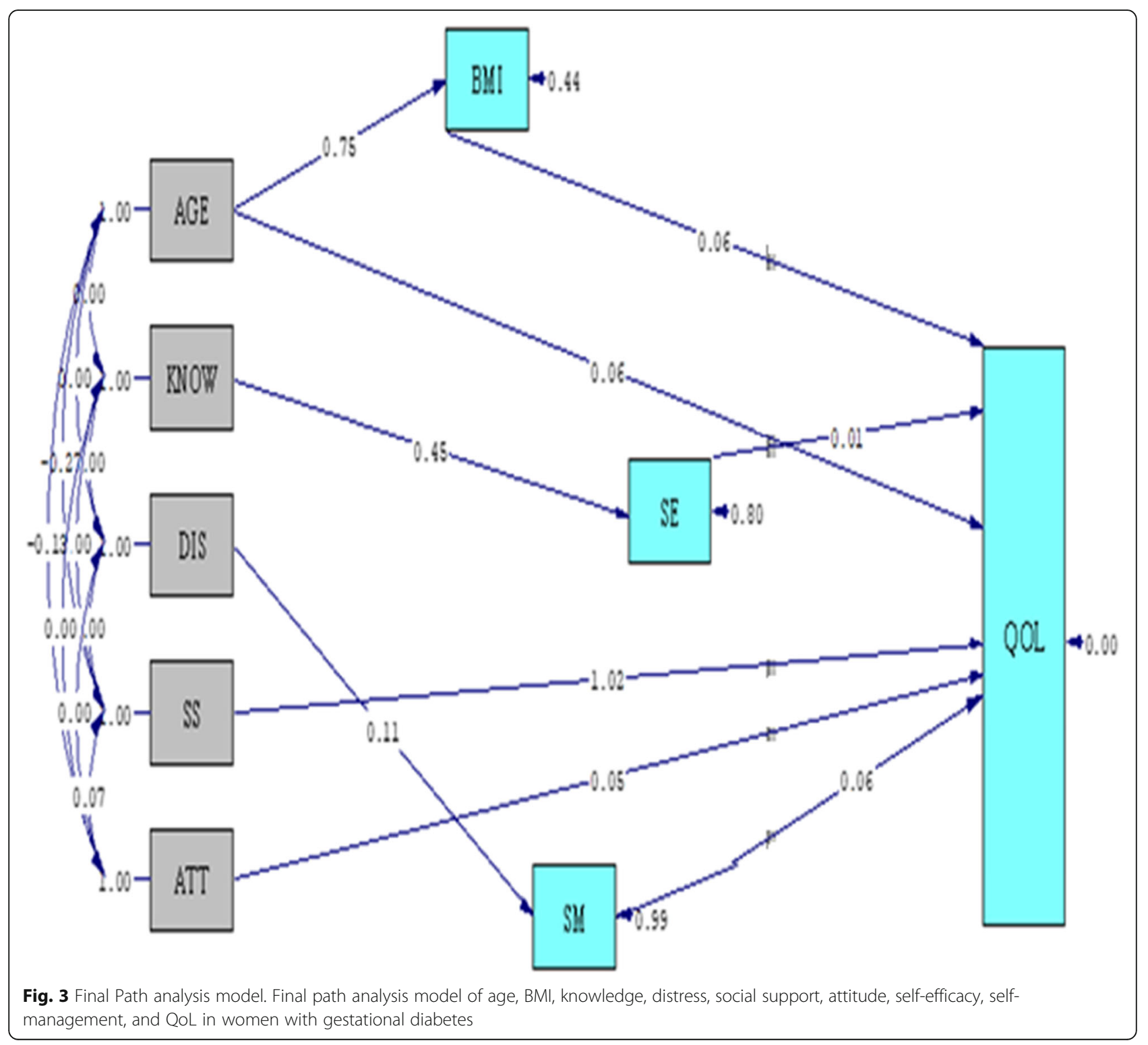


Table 3 Path Coefficients for study Predictors on QoL in patients with gestational diabetes

\begin{tabular}{llll}
\hline Predictors & Effects & & \\
\hline & Direct & Indirect & Total \\
AGE & 0.06 & 0.45 & 0.51 \\
BMI & 0.06 & & \\
KNOW & & 0.0045 & 0.0045 \\
SS & 1.02 & & 1.02 \\
ATT & 0.05 & & 0.05 \\
SE & 0.01 & & 0.01 \\
SM & 0.06 & & 0.06 \\
Diss & & 0.00066 & 0.00066 \\
\hline
\end{tabular}

Obviously, the existence of diabetes along with pregnancy increase adverse outcomes of aging in this period, leading to further loss of QoL.

In this study, age also indirectly influences the quality of life through impact on BMI. Higher BMI in prepregnancy period is associated with a higher rate of abnormal glucose tolerance [42] which can affect the QoL. Salehi et al. study also showed a significant correlation between BMI and QoL [43].

Based on the results of this study, among variables that directly influence on QoL, SS had the greatest impact on the QoL in women with GD. SS during pregnancy are a protective factor in mothers and help them cope with stressful events in life. This factor during pregnancy not only affects the health of mothers but also pregnancy outcomes. The management of diabetes during pregnancy is identified as a stressful event [44].

Due to the results of this study, pregnancy distress also influenced the QoL through SM. Based on the results of the current study, to improve the QoL in women with GD; patients should overcome the pregnancy distress and accomplish SM behaviors. The study of Razee et al. [45] showed that the ability of women with GD to follow a healthy lifestyle depends on their mental health, social and cultural support.

The results of the current study indicated that knowledge had indirect effects on QoL through SE in women with GD. Other studies have also shown that, in diabetes patients, knowledge alone does not initiate health promotion behaviors [46, 47]. Regarding diabetes SM, there was a consensus that patients should be trained to take care of themselves, and not only knowledge but the

Table 4 Goodness of fit Indices for the model

\begin{tabular}{llllllll}
\hline Fitting Index & $\mathrm{X}^{2}$ & DF & RMSEA & GFI & NFI & CFI & IFI \\
\hline Model Index & 181.14 & 36 & 0.0003 & 0.99 & 1 & 1 & 1 \\
Acceptable Range & X2/df $<5$ & $<0.05$ & $>0.9$ & $>0.9$ & $>0.9$ & $>0.9$
\end{tabular}

IFI Incremental fit indices, NFI Normed-fit index, GFI Goodness-of-fit statistic, RMSEA Root mean square error of approximation, $\times 2$ chi-square
Table 5 Mean and SD of the study variables

\begin{tabular}{lllll}
\hline Variables & Mean & SD & Min & Max \\
\hline Know & 7.29 & 2.014 & 5 & 13 \\
Attitude & 47 & 4.27 & 32 & 60 \\
SE & 106.69 & 24.29 & 19.20 & 158 \\
SS & 93.28 & 22.31 & 36 & 149 \\
Distress & 21.20 & 9.34 & 5 & 48 \\
SM & 14.25 & 4.06 & 4 & 22.01 \\
\hline
\end{tabular}

ability to manage the disease is necessary to control the disease [48].

SE was another variable that directly affected the QoL. SE plays a key role in the ability of people. Bandura defines SE as a person's belief in his ability to perform specific behavior. Yale (2015) stated that SE in diabetic patients is one of the predictors of the SC behaviors in them [49]. Therefore, we should pay attention to improve SE in health promotion interventions. We can use appropriate role modeling, verbal persuasion, and dividing tasks into smaller steps. In line with the results of the current study. Moheby et al. [50] demonstrated that the SE stimulates motivation in diabetic patients and has a direct impact on health promoting behaviors. Mrovati et al. also indicated that SE alone explains $38 \%$ of the variance in SC behaviors [51].

It is clear that SC behaviors are associated with a higher QoL in patients. Based on the results of this study, SC behaviors had a significant effect on QoL. Similar to many chronic diseases, diabetic patients require both continuous management of their disease and the proper SC behaviors. SC behaviors have significant impact on QoL in diabetic patients [52]. Babazadeh et al. (2017) showed that SC behaviors are the essential component of controlling the disease and improving the QoL in patients with diabetes [21].

Knowledge was another variable which indirectly affected on QoL through SE [53]. Knowledge is considering as one of an important resource for avoiding complications and improving QoL in diabetic patients [23]. Due to Bohanny et al. study diabetic knowledge, obtaining diabetes education and employment status explained $11.8 \%$ of the variance in SE [54]. In the current study, $90.3 \%$ of the subjects were house worker.

Contrary to Kueh et al. results [17], there was no statistically significant relationship between knowledge and attitude and they were eliminated from the final fitted model. However, attitude directly influenced QoL, and knowledge had an impact on the QoL through SE. Ardena et al. (2010) showed that Knowledge alone is not enough to change lifestyle and improve QoL in diabetic patients, but requires psychosocial factors, such as attitude and SE [55]. There is a significant and positive relationship between attitude and QoL in diabetic patients. 
This study had some strengths and limitations; one of the major strengths was the fact that to the best of our knowledge, this is the first study that investigates the direct and indirect effects of the variables on the QoL among pregnant woman with gestational diabetes. Convenience sampling method is one of the limitations of this study. It may lead to bias in the conclusion and generalization of the results of this study. Given that this study carried out among Iranian patients, the results study might not be generalized to all pregnant women with gestational diabetes.

\section{Conclusion}

SS had the greatest impact on the QoL in women with GD. Obviously, providing all the requirements to support patients with GD can help them overcome problems and improve their QoL. Also, distress is one of the factors that negatively affect the QoL through SM behaviors. A variety of therapeutic and supportive methods to reduce distress in patients can be used to enhance SM behaviors and improve the QoL in them.

\section{Abbreviations}

ATT: Attitude; BMI: Body mass index; CFI: Comparative fit index; DISS: Distress; GDM: Gestational diabetes mellitus; GFI: Goodness of fit index; IFI: Incremental fit indices; KNOW: Knowledge; NFI: Normal fit index; QoL: Quality of life; RMSEA: Root mean square error of approximation SC: Self-care; SE: Self efficacy; SM: Self-management; SS: Social support

\section{Acknowledgements}

The authors would like to thank all the patients for their participation in the study.

\section{Authors' contributions}

SA: collected the study data and contributed to statistical analysis and interpreted the findings. LS has supervised the study; contributed to the study design and conducted the analysis and write the manuscript ZM: analyzed the data and draft the manuscript. AMB: helped in data interpretation and data analysis, The author(s) read and approved the final manuscript.

\section{Funding}

This study conducted without any funding

\section{Availability of data and materials}

The current study datasets and analysis sheets are available and will be provided due to reasonable request.

\section{Ethics approval and consent to participate}

Ethical Committee of Alborz University of Medical Sciences approved the study (approval number: 1396.91-08.06.96). All the participants signed the written consent forms. All the participations were assured regarding their privacy in this study and informed about volunteer entering in the study and willingness to exclude from the study at any time.

\section{Consent for publication}

Not applicable.

\section{Competing interests}

The authors declare that there is not any conflict of interest.

\section{Author details}

'Department of Health Education, School of Public Health, Alborz University of Medical Sciences, Karaj, Iran. ${ }^{2}$ Department of Health Education and Promotion \& Research center for Health, Safety and Environment, Alborz
University of Medical Sciences, Karaj, Iran. ${ }^{3}$ Department of Health Education \& Promotion, School of Public Health, Alborz University of Medical Sciences, P.O. Box 3146-883811, Karaj, Iran. ${ }^{4}$ Social Determinants of Health Research Center \& School of Nursing and Midwifery, Alborz University of Medical Sciences, Karaj, Iran. ${ }^{5}$ Department of Epidemiology \& Research Center for Environmental Pollutant, Qom University of Medical Sciences, Qom, Iran.

Received: 30 January 2019 Accepted: 12 February 2020

Published online: 18 February 2020

\section{References}

1. Hajifaraji M, Dolatkhah N. Gestational Diabetes Mellitus and Associated Challenges from the Perspective of Nutrition Science: A Review Article. J Mazandaran Univ Med Sci. 2017;27:202-24.

2. Landon MM. A multicenter randomized trial of treatment for mild gestational diabetes. N Engl J Med. 2009;361:1339-48.

3. Almasi SZ, Salehihiya $\mathrm{H}$. The prevalence of gestational diabetes mellitus in Iran (1993-2013)-Asystematic review. J Isfahan Med Sch. 2014;32:1396-412.

4. Zhu Y, Zhang C. Prevalence of gestational diabetes and risk of progression to type 2 diabetes: a global perspective. Curr Diab Rep. 2016;16:7.

5. Henriksen T. The macrocosmic fetus: a challenging current obstetrics. Acta Obstet Gynecol Scand. 2008:87:134-45.

6. Reece EA. The fetal and maternal consequences of gestational diabetes mellitus. J Matern Fetal Neonatal Med. 2010;23:199-203.

7. Negrato CA, Mattar R, Gomes MB. Adverse pregnancy outcomes in women with diabetes. Diabetol Metab Syndr. 2012:4:41.

8. Ju H, Rumbold AR, Willson JJ, Crowther CA. Borderline gestational diabetes mellitus and pregnancy outcomes. BMC Pregnancy Childbirth. 2008;8:31.

9. Kim C. Gestational diabetes mellitus and risk of future maternal cardiovascular disease. Expert Rev Cardivasc Ther. 2010;8:1639-41.

10. Malcolm J. Through the looking glass: gestational diabetes as a predictor of maternal and offspring long-term health. Diabetes Metab Res Rov. 2012;28: 307-11.

11. Salahudeen MS, Koshy AM, Sen S. A study of the factors affecting time to onset of lactogenesis II after parturition. J Pharm Res. 2013;6:68-72.

12. Mpondo BC, Ernest A, Dee HE. Gestational diabetes mellitus: challenges in diagnosis and management. J Diabetes Metab Disord. 2015;14:42.

13. Ahmadi A, Hasanzadeh J, Rahimi M, Lashkari L: Effective factors in the quality of life of patients with type 2 diabetes in Chaharmahal \& Bakhteyari province. JNKUMS 2011, $3: 7-13$. [Persian].

14. Trikkalinou A, Papazafiropoulou AK, Melidonis A. Type 2 diabetes and quality of life. World J Diabetes. 2017;8:120-9.

15. Vares $Z$, Asayesh $H$, Aliakbarzade arani Z, Sharififard F. Related factors in the quality of life of diabetic elderlies. ljdld 2017, 16 (5) :261-268 [Persian].

16. Fowler MJ. Microvascular and macro vascular complications of diabetes. Clin Diabetes. 2008;26:77-82.

17. YC K, Morris T, Borkols E, Shee M. Modeling of Diabetes knowledge, attitudes, self-management and quality of life - A Cross Sectional Study. Health Qual Life Outcomes. 2015;13:129.

18. Boorgar ER, Besharat MA, Mohajer MR, Talepasand S: Predictive role of selfefficacy, belief of treatment effectiveness and social support in diabetes mellitus self-management. Iran J Psychiatr Clin Psychol 2011, 17: 232-240 [Persian].

19. Piette JD, Kerr EA. The impact of comorbid chronic conditions on diabetes care. Diabetes Care. 2006;29:725-31.

20. Rubin RR, Peyrot M. Quality of life and diabetes. Diabetes Metab Res. 1999;9: 205-18.

21. Babazadeh T, Dianatinasab M, Daemi A, Nikbakht HA, Moradi F, Ghaffari-fam S. Association of self-care behaviors and quality of life among patients with type 2 diabetes mellitus: Chaldoran county, Iran. Diabetes Metab J. 2017:41: 449-56.

22. Goudarzi M, Ebrahim Zadeh I, Rabi AR, Saeidipour B, Asghari Jafarabadi M. Assessment of knowledge, attitude, practice and self-efficacy of diabetic patients in Karaj, Iran. Iran Diab Metab J. 2011;11:269-81.

23. Khadivarzadeh T, Hoseinzadeh M, Azhari S, Esmaily H, Akhalaghi F, Sadar MA. Effects of self-care education on perceived stress in women with gestational diabetes under insulin treatment. Evid Based J. 2015:5:7-18.

24. Salehi L, Haidari F: Efficacy of PRECEDE model in promoting nutritional behaviors in a rural society. Irje 2011, $6: 21-27[$ Persian].

25. Ghasemi pour M, Ghasemi V, Zamani A R. Study of life quality in the patients with diabetes referred to Khorramabad Shohada hospital in 2008. Yafte 2009, $11: 125-133$ 
26. Bazzaaian S, Rajab A:Self-efficacy, social support and quality of life in patients with type 2 diabetes. J behavl Sci 2012, 3: 25-39[Persian]

27. Almasi SZ, Salehiniya $H$ : The prevalence of gestational diabetes mellitus in Iran (1993-2013) A systematic review. J Isfahan Med Sch 2014, 32: 13961412. [Persian]

28. Elmurugan S, Arounassalame B. What do mothers know about gestational diabetes: knowledge and awareness. Ind J Obsterrics Gynecol Res. 2016;3:393-6.

29. Anderson RM, Fitzgerald JT, Funnell MM, Gruppen LD. The third version of the diabetes attitude scale. Diabetes Care. 1998;21:1403-7.

30. Parardly N, Greening L, Ott J, Holderby A, Atchison J. Adolescents health attitudes and adherence to treatment for insulin dependent diabetes mellitus. J Dev Behav Pediatr. 1998;19:31-7.

31. Naderimagham SH, Niknami SH, Abolhassani F, Hajizadeh E, Montazeri A Development and psychometric properties of a new social support scale of self-care in middle-aged patients with type II diabetes(S4-MAD). BMC Public Health. 2012;12:1035.

32. Pop VJ, Pommer AM, PoP - Purceleanu M, Wijnen HA, Bergink V, Pouwer F. Development of the Tilburg pregnancy distress scale: the TPDS. BMC Pregnancy Childbirth. 2011;11:80.

33. Schmitt A, Gahr A, Hermanns N, Kulzer B, Huber J, Haak T. The diabetes Selfmanagement questionnaire (DSMQ): development and evaluation of an instrument to assess diabetes self-care activities associated with glycemic control. Health Qual Life Outcomes. 2013;11:138.

34. Power M, Park M. The World Health Organization Quality of Life Assessment (WHOQOL): development and general psychometric properties. Soc Sci Med 1998;46:1569-85.

35. Nejat S, Montazeri A, Holakouie Naieni K, Mohammad K, Majdzadeh SR. The World Health Organization quality of life (WHOQOL-BREF) questionnaire: translation and validation study of the Iranian version. J Sch Public Health Inst Public Health Res. 2006:4:1-12

36. Stojanović M, Cvetanović G, Anđelković-Apostolović M, Stojanović D, Rančić N. Impact of socio-demographic characteristics and long-term complications on quality of life in patients with diabetes mellitus. Cent Eur J Public Health. 2018;26:104-10.

37. Lyrakos G, Hatziagelaki E, Spinaris B, Damigos D, Spyropoulos I, Kostopanagiotou $\mathrm{G}$. The comparison of fatigue between patients with diabetes mellitus, psychiatric outpatients and general population in Greece. Eur Psychiatry. 2012;27(Suppl):1.

38. Kumar R, Krishan P, Jhajj R. Health-related quality of life and factors affecting it in type-2 diabetic nephropathy patients: a cross sectional observational study. Int J Res Med Sci. 2016;4:1511-7.

39. Huang L. Maternal age and risk of stillbirth: a systematic review. CMAJ. 2008; 178:165-72.

40. Maheshwari A, Porter M, Shetty A, Bhattacharya S. Women's awareness and perceptions of delay in childbearing. Fertil Steril. 2008;90:1036-42.

41. Lindsay G, Inverarity K, McDoely JRS. Quality of life in people with type 2 diabetes in relation to deprivation, gender, and age in a new communitybased model of care. Nurs Res Pract. 2011:1-8.

42. Arjmandi Far M, Ziaei S, Kazemnejad A. The impact of maternal age, prepregnancy body mass index, weight gain and parity on glucose challenge test(GCT). Int J Fertil Steril. 2012;5:207-2010.

43. Salehi L, Slaki S, Alizadeh L.: Health related Quality of life among elderly member of elderly centers in Tehran. Irje 2012; 8:14-20. [Persian].

44. Persson M, Winkvist A, Mogren I. From stun to gradual balance' - women's experiences of living with gestational diabetes mellitus. Scand J Caring Sci. 2010;24:454-62.

45. Razee H, Van der Ploeg HP, Blignault I, Smith BJ, Bauman AE, McLean M, Wah Cheung N. Beliefs, barriers, social support, and environmental influences related to diabetes risk behaviors among women with a history of gestational diabetes. Health Promot J Austr. 2010;21:130-7.

46. Heisler M, Piette JD, Spencer M, Kieffer E, Vijan S. The relationship between knowledge of recent $\mathrm{HbA1c}$ values and diabetes care understanding and self-management. Diabetes Care. 2005;28:81622.

47. Susan LN. Recommendation for healthcare system and self-management education interventions to reduce morbidity and mortality from diabetes. Am J Prev Med. 2002;22:10-4

48. Powers MA, Bardsley J, Cypress M, Duker P, Funnell MM, Fischl AH, Maryniuk MD, Siminerio L, Vivian E. Diabetes self-management education and support in type 2 diabetes: a joint position statement of the American Diabetes Association, the American association of diabetes educators, and the academy of nutrition and dietetics. Clin Diabetes. 2016;34:70-80.
49. Yang S, Hsue C, Lou Q. Does patient empowerment predict self-care behavior and glycosylated hemoglobin in Chinese patients with type 2 diabetes? Diabetes Technol Ther. 2015;17:343-8.

50. Moheby S, Azadbakht L, Feizi A, Sharifirad GH, Kargar M. Review the key role of self-efficacy in diabetes care. J Educ Health Promot. 2013;2:36.

51. Morowati Sharifabad M, Rouhani Tonekaboni N. Perceived self-efficacy in self-care behaviors among diabetic patients referring to Yazd diabetes research center. JBUMS. 2009;15:91-9.

52. Debaty I, Halimi S, Quesada JL, Baudrant M, Allenet B, Benhamou PY. A prospective study of quality of life in 77 type 1 diabetic patients 12 months after a hospital therapeutic educational programme. Diabetes Metab. 2008; 34:507-13.

53. Bohanny W, Wu SF, Liu CY, Yeh SH, Tsay SL, Wang TJ. Health literacy, selfefficacy, and self-care behaviors in patients with type 2 diabetesmellitus. J Am Assoc Nurse Pract. 2013:25:495-502.

54. Ardena GJ, Paz-Pacheco E, Jimeno CA, Lantion-Ang FL, Paterno E, Juban N. Knowledge, attitudes and practices of persons with type 2 diabetes in a rural community: phase I of the community-based diabetes selfmanagement education (DSME) program in San Juan, Batangas, Philippines. Diabetes Res Clin Pract. 2010;90:160-6.

55. Kassahun T, Gesesew H, Mwanri L, Eshetie T. Diabetes related knowledge, self-care behaviours and adherence tomedicationsamong diabetic patients in Southwest Ethiopia: a cross-sectional survey. BMC Endocr Disord. 2016; 31(16):28

\section{Publisher's Note}

Springer Nature remains neutral with regard to jurisdictional claims in published maps and institutional affiliations.
Ready to submit your research? Choose BMC and benefit from:

- fast, convenient online submission

- thorough peer review by experienced researchers in your field

- rapid publication on acceptance

- support for research data, including large and complex data types

- gold Open Access which fosters wider collaboration and increased citations

- maximum visibility for your research: over $100 \mathrm{M}$ website views per year

At $\mathrm{BMC}$, research is always in progress.

Learn more biomedcentral.com/submissions 